\title{
SOBERANÍA Y CONTINUIDAD CULTURAL CARIBEÑA Y LATINOAMERICANA: MARTÍ Y DARÍO EN "LE PREGUNTARON POR LOS PERSAS" DE FERNÁNDEZ RETAMAR
}

Alberto Rivera Vaca

\section{(c) $(7) \Theta$}

Doi: https://doi.org/10.15517/rfl.v46i2.42269

URL: https://revistas.ucr.ac.cr/index.php/filyling/index 



\title{
SOBERANÍA Y CONTINUIDAD CULTURAL CARIBEÑA Y LATINOAMERICANA: MARTÍ Y DARÍO EN "LE PREGUNTARON POR LOS PERSAS" DE FERNÁNDEZ RETAMAR
}

\author{
SOVEREIGNTY AND CULTURAL CONTINUITY IN \\ THE CARIBBEAN AND LATIN AMERICA: MARTÍ \\ AND DARÍO IN "LE PREGUNTARON POR LOS \\ PERSAS” BY FERNÁNDEZ RETAMAR
}

\begin{abstract}
RESUMEN
La poesía del cubano Roberto Fernández Retamar (1930) conserva vínculos con el pensamiento ideológico y poético de José Martí y Rubén Darío. Desde la poesía y, previo a sus principales ensayos, como Caliban, Fernández Retamar se erige como custodio crítico de la tradición intelectual caribeña y latinoamericana. En "Le preguntaron por los persas", asume ya de su propia tradición conceptos que refieren a la función de la poesía, la circunstancia histórica, el cosmopolitismo y el anticolonialismo para preservar la soberanía cultural e intelectual de Cuba y el resto de la región. Este ensayo está elaborado a través del análisis textual de la poesía, y las categorías que lo guían se basan en el pensamiento de Martí, Darío y Fernández Retamar.

Palabras clave: poesía hispanoamericana; modernismo; anticolonialismo; historicidad; integración caribeña y latinoamericana.
\end{abstract}

Alberto Rivera Vaca

\begin{abstract}
The poetry of the Cuban Roberto Fernández Retamar (1930) has links with the ideological and poetical thought of José Martí and Rubén Darío. Through his poetry, and not only from his essays like Caliban, Fernández Retamar stands as a custodian of the Caribbean and Latin American intellectual tradition. From this heritage, in "Le preguntaron por los persas", he assumes concepts that refer to the function of poetry, historic circumstance, cosmopolitanism, and anti-colonialism to preserve cultural and intellectual sovereignty of Cuba and the rest of the region. This essay is elaborated through textual analysis of the poetry and the categories that guide it are based on the thought of Martí, Darío, and Fernández Retamar.

Keywords: Spanish American poetry; modernism; anti-colonialism; historicity; Caribbean and Latin American integration.
\end{abstract}

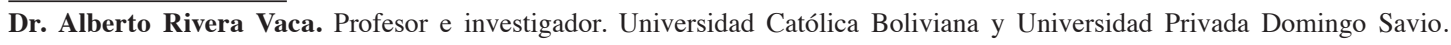
Bolivia.

Correo electrónico: alberto.rivera@docentes.ucbtja.edu.bo / tj.alberto.rivera.v@upds.net.bo

Recepción: 21- 03- 19

Aceptación: 05- 11- 19 


\section{Introducción}

Roberto Fernández Retamar (Cuba, 1930-2019) es uno de los poetas y ensayistas más representativos del Caribe y de América Latina. En su obra ensayística más importante existen "estrategias de la memoria cultural" latinoamericana y hemisférica (Machín, 2000, p. 158). Además, "sus modos de apropiar y recuperar la tradición constituyen, en parte, el secreto de la presencia de muchos de sus conceptos y propuestas en debates actuales" (Moraña, 2002, p. 567). No obstante, estas estrategias de apropiación y recuperación de la tradición cultural regional se evidencian, primeramente, desde la segunda etapa de su poesía iniciada en 1958, antes de, por ejemplo, la publicación de su ensayo Caliban (1971). Aquella crítica que ha estudiado los versos del pensador cubano ha relacionado con acierto la poesía de Fernández Retamar con la Revolución Cubana, debido a que la autodefinición del hablante poético en sus versos "existe en relación a su mundo concreto": Cuba (Bornstein, 1985, p. 108)1. Sin embargo, Fernández Retamar declara que cuando habla de aquella parte de la historia que le tocó experimentar, la Revolución, lo ha hecho también "pensando en la humanidad" (Marras, 1992, p. 331).

Si en sus versos el yo poético se define en relación con el contexto que le rodea Cuba-, hay que considerar que aquel mundo concreto con el que igualmente se define incluye al resto de su América; esta es una temática poco estudiada, pero presente en sus versos antes que en su ensayística. Sobre esto, a pesar de más de medio siglo de producción poética, la crítica pone aún mayor atención a su labor ensayística; sin embargo: "No es posible entender la pasión auténtica y disciplinada, la energía, la vitalidad y el dinamismo que caracterizan la prosa de teoría y critica literarias de Fernández Retamar sin leer su poesía” (Ellis, 1986, p. 1225). Probablemente, "muchos de sus poemas sirvan para comprender mejor este complejo siglo XX que algunos de sus ensayos" (Arcos, 2001, p. 19).

En su poesía, primeramente, Fernández Retamar custodia de forma crítica la continuidad cultural e intelectual de América Latina y el Caribe, ya que considera a José Martí (Cuba, 1853-1895) como su maestro absoluto y a Rubén Darío (Nicaragua, 1867-1916) como padre moderno del idioma castellano. Gracias a Martí y a Darío, logra "imbricarse dentro de la modernidad" americana (Arcos, 2001, p. 26). Algunas características temáticas y de estilo martianas y rubendarianas se encuentran en poemas como "La poesía, la piadosa" de Sí a la Revolución (1958-1962), "Le preguntaron por los persas" de Buena suerte viviendo (1962-1965), "R.D.” de Que veremos arder (1966-1969) y otros. En "Le preguntaron por los persas” -“espléndido texto”, según Dalton (1967, p. 132)- Fernández Retamar recupera la idea martiana de la importancia de la función de la poesía, más allá del pensamiento y el estilo,

1 Sobre su primera poesía, la crítica observa en el texto poético la naturaleza del poeta: suave, preciso, tierno, didáctico y sobrio (Vitier, 1971). Para la segunda época, esa ternura se encuentra en las situaciones más difíciles (Dalton, 1963), y surgen lo coloquial, lo simpático y las disyuntivas de la Revolución (Dalton, 1967). Los estudios enfatizan el testimonio de la Revolución, la visión histórica, la experiencia personal y la conciencia crítica (Gonzales, 2008; Wong, 1976). Una poesía nacional (Ellis, 1986), sociopolítica, internacional (Bornstein, 1985) y existencial (Fernández Moreno, 1982). Pero también una que habla de la familia y los seres queridos (Barquet, 2002; Ellis, 1986). Una poesía comprometida con lo artístico y lo poético, además del carácter referencial (García, 1970; Rivera, 2015; Rostagno, 1986), nutrida por la intertextualidad (Barquet, 2002; Bornstein, 1985), y ligada a una conciencia del lenguaje y a una tradición poética hispanoamericana (Rodríguez, 2000). 
y la circunstancia histórica específica como la soberanía y la continuidad cultural. Convergen en este texto rasgos encontrados en otros poemas y, especialmente, en ensayos posteriores; por eso es el eje articulador de esta investigación.

Para tratar la soberanía y continuidad cultural de América Latina y el Caribe, Fernández Retamar recurre a la intertextualidad, característica recurrente en la segunda etapa de su poesía. Dedica "Le preguntaron por los persas" a Darío, asumiendo procedimientos modernistas y elaborando una relación intertextual con los versos de "A Roosevelt" y "Los cisnes". Con claro signo modernista, recurre a un contexto Oriental para referir su propia circunstancia y asume la preocupación de Darío con respecto a la soberanía territorial y cultural de su América. Vincularé "Le preguntaron..." con otros poemas y ensayos de Fernández Retamar, ya que tanto su lírica como su ensayística son una proyección mutua, a partir de la cual se sustenta y desarrolla su pensamiento intelectual.

Fernández Retamar expresa su inquietud patriótica desde el primer periodo de su poesía, como en Elegía como un himno (1950), dedicado a Rubén Martínez Villena (18991934), opositor al gobierno de Gerardo Machado. En la segunda etapa aparece claramente el tema de la soberanía nacional, cavilación que abarca luego al resto de la región americana en oposición a potencias coloniales. Bien lo observa Rodríguez que en "Última estación de las ruinas" de Sí a la Revolución (1958-1962) existe:

una consciente confrontación entre Cuba y Europa como entidades generadoras de sus propias culturas y sus propias memorias: eso que hoy llamamos la 'identidad cultural'. Lejos de desaparecer [...] se irá ampliando en el latinoamericanista Fernández Retamar, hasta convertirse en un motivo esencial de su obra, poética y ensayística (2000, p. 19).

En Sí a la Revolución aparece este tema en relación con los Estados Unidos. Por tanto, la reflexión poética de Fernández Retamar se extiende de la isla hacia la humanidad más próxima, la región concreta que lo circunda.

\section{José Martí, maestro absoluto}

Fernández Retamar es reconocido en su país como uno de los principales exégetas cubanos de la obra de Martí (Arcos, 2001), ya que pocos han estudiado y escrito al respecto de forma tan extensa como él, hasta el punto de producir líneas de estudio posteriormente transitadas por otros. Durante los sesenta escribió "Lectura de Martî" (1961) y "Martí en su (tercer) mundo" (1965), en la siguiente década Lectura de Martí (1972) e Introducción a José Martí (1978), y en los ochenta estudió la poesía de su compatriota. Martí es la figura principal en su pensamiento, lo considera su maestro absoluto (Fernández Retamar, 2005, p. 94) y, en sus palabras, es "la figura central de nuestra América" (como se citó en Gordon, 1992, p. 678). Indica que tuvo la "necesidad de explicar un fenómeno tan complejo y tan original como la Revolución Cubana a luz del pensamiento y de la obra de Martî" compuesta por poemas, ensayos y discursos (como se citó en Gordon, 1992, p. 678). Y resume: "Creo que el proceso complejo que ocurre en Cuba no se entiende si se desconoce la obra de José Martí" (como se citó en Gordon, 1992, p. 678).

La figura de Martí es inmensa, pues fuera de Cuba ha sido igualmente estudiada durante la década de los ochenta y noventa por pensadores como el uruguayo Ángel Rama (1926-1983), de la misma generación de Fernández Retamar, o por otros investigadores de generaciones subsiguientes como el puertorriqueño Julio Ramos. Rama, por ejemplo, establece 
una interpretación teórica sobre la obra de Martí, una "dialéctica de la modernidad" (Rama, 1974) que, para Ramos, "resulta decisiva para el proyecto martiano de una modernidad contrahegemónica” (Ramos, 2014, p. 7).

Fernández Retamar considera fundamentales los siguientes principios de la obra martiana:

a) La función de la poesía: Martí "no quería que se le tomara por poeta en verso antes que por poeta en actos" y "por mucho que a Martí le importó la forma y el pensamiento, ante todo le interesó la función" de la poesía en relación a la sociedad. Por eso, "enlazó forma y pensamiento apuntando a una función" (Fernández Retamar, 2007, pp. 239-240), para esto elaboró textos que son al mismo tiempo literarios y políticos (Fernández Retamar, 1995, p. 242).

b) Literatura de circunstancia y conciencia histórica: según Fernández Retamar, Martí asumió tempranamente que "las realidades literarias deben verse en estrecha relación con determinadas realidades históricas" (1995, p. 264). Rechazó en la novela "un realismo empobrecedor" y practicó, contrariamente, "un realismo creador de alto vuelo", un tipo de literatura factual o testimonio, sostiene Fernández Retamar. Para Martí, este realismo debía "Recoger toda la savia de la vida" (Fernández Retamar, 1995, pp. 250-251), pues consideraba que la literatura estaba en relación estrecha con la historia y que la imitación arbitraria de otras tradiciones literarias producía una separación entre literatura y realidad. Al respecto, dijo en 1875: "La imitación servil extravía, en economía como en literatura y en política" (como se citó en Fernández Retamar, 1995, p. 265).

c) Cosmopolitismo: Martí fue un escritor cosmopolita y cultivado; vivió prolongadamente en varios países de América y Europa; se nutrió "de muchas literaturas", desde las clásicas hasta las modernas; y escribió en español, francés e inglés. De ahí que haya aseverado que: "Conocer diversas literaturas es el medio mejor de liberarse de la tiranía de algunas de ellas" aunque aquello no implicaba "la admiración servil a extraños rimadores, la aplicación cómoda y perniciosa de otros mundos" (como se citó en Fernández Retamar, 1995, p. 269). Este interés por otras tradiciones culturales revela el ímpetu cosmopolita típico de aquella época entre los intelectuales hispanoamericanos. Martí sigue el trabajo de los poetas modernistas, hasta incluso pensar en escribir un libro acerca de aquellos "nuevos poetas de América" (Fernández Retamar, 1995, pp. 260-263). Sugiere que los escritores modernistas asumen "algunos de los aspectos de la prédica martiana", como el esmero y la pulcritud en la escritura, a pesar de evitar toda referencia histórica a América en su poesía inicial, refugiándose en otras culturas (1995, p. 265). Rama (1974) enfatiza: "Martí fue situado en el arranque de la ola modernista de la que será padre... Este padre que no sabrá de su larga descendencia, será visto en función de hijo de un proceso histórico-literario anterior" (p. 130).

d) Oposición al colonialismo: Martí trabaja por la independencia de Cuba, se opone al colonialismo español que dominaba en Cuba y Puerto Rico y, también, a los proyectos de expansión estadounidenses, mediante la censura enérgica de las primeras conferencias panamericanas en Washington (Fernández Retamar, 2007). De esta manera: "Lo que inicia es la toma de conciencia de una época" (Fernández Retamar, 1995, p. 277) y, como fundador ideológico, "pertenece a la exigua y preciosa estirpe de los fundadores de grandes creencias universales" (Fernández Retamar, 2007, p. 246), pues "no es solo el último de los grandes libertadores de nuestro continente en el siglo diecinueve, sino el primero de los libertadores de nuestra América en el siglo veinte" (como se citó en Marras, 1992, p. 311). De "ahí que Martí sea uno de los primeros escritores modernos latinoamericanos” (Ramos, 2009, p. 58). 


\subsection{Le preguntaron por los persas: Persia y las polis griegas}

El pensamiento martiano resuena en "Le preguntaron por los persas" y en otros textos líricos de Fernández Retamar. "Le preguntaron..." está elaborado como una alegoría histórica referente a sucesos pretéritos para hablar figurativamente de eventos actuales. Fernández Retamar tiene una amplia formación intelectual y la referencia al pasado en este poema exige considerar la extensa y conflictiva relación entre Persia y Grecia ${ }^{2}$. La siguiente explicación de "Le preguntaron...", aunque sea descriptiva, resulta necesaria para revelar el pensamiento temprano del poeta antes de la elaboración de su principal obra ensayística. En este poema no existen ambigüedades entre la expresión y el contenido de los signos, pero al pasar al plano ideológico y cultural, los valores semióticos se actualizan en significativos valores semiológicos. La relación entre la expresión "Persia" en el texto es una analogía de "Estados Unidos de Norte América"; igualmente, la expresión "isla" con respecto a "Cuba". Las expresiones "salpicadura de nuestras poblaciones" sobre el mar y la referencia a otros "millones de hombres" corresponden al contenido "Caribe" y "América Latina". Al homologar estos dos campos, Persia (EE. UU.) y Grecia (Caribe / América Latina), podemos dilucidar y comprender ampliamente criterios fundamentales del autor. El poema habla del inmenso poder persa y la heroica resistencia griega que impidió la conquista de su territorio. Mediante esta figuración, el poeta escribe con una conciencia histórica, con la cual detalla la relación tensa de varios siglos entre Cuba y Estados Unidos, y la resistencia cubana por su soberanía territorial y cultural, actitud que se extiende al Caribe y América Latina. Esta concepción poética inyectada de conciencia histórica, donde la poesía se robustece en contenido, no necesariamente en extensión, aparece previamente en poemas como "La poesía, la piadosa" (Rivera, 2015). En aquella arte poética, Fernández Retamar considera la poesía como "torso puro de ayer", la cual no "se separa de la atroz vigilia", pues ella "no sabe sino contar, sino / Apegarse a las cosas torpemente" (2009, p. 125).

"Le preguntaron..." es un poema conversacional, contiene la respuesta oral, en forma de discurso, de un experimentado ateniense a un grupo de conciudadanos que le inquirieron por los persas. El título plantea desde un inicio que la respuesta resulta de la conversación y la indagación; además, el texto es un discurso con tono oratorio, donde el yo poético manifiesta su elocuencia contando la relación histórica entre Grecia y Persia. El registro conversacional se encuentra en otros versos, del segundo periodo de su poesía, en forma de cartas dirigidas a pioneros, familiares y compañeros de trabajo. Lo conversacional en "Le preguntaron..." busca

2 La dinastía aqueménida, bajo el liderazgo de Ciro el Grande, convirtió a Persia en el primer imperio mundial, ya que logró dominar un gran territorio del Asia durante los siglos $\mathrm{V}$ a. C., y alcanzó naturalmente las orillas de varios mares. Griegos y persas comenzaron a tener conflictos durante los primeros años del siglo V a. C. (Lazenby, 2007). Luego de derrotar al reino de Lidia, Ciro había adquirido el control de las ciudades griegas de Jonia en la Grecia continental del Asia menor. Cuando Darío heredó el trono, los jonios se sublevaron con el apoyo de Atenas. Desde entonces, Atenas se convirtió en el blanco de los ataques persas. Darío preparó la primera invasión sobre la Grecia peninsular alrededor del año 491, enfrentamiento conocido como la Batalla de Maratón (Lazenby, 2007). A esta batalla le siguieron otras importantes. Persia se destacaba por sus conocimientos marítimos y poseía una poderosa marina de guerra. El 479 a. C., Jerjes, hijo de Darío, dirigió otra incursión en la isla de Salamina, específicamente en el golfo Sarónico, donde se enfrentaron navíos griegos y persas. Persia resultó perdiendo sus navíos y se retiró de la batalla (Herodoto, 1974). Las guerras entre persas y griegos duraron mucho tiempo hasta el triunfo de Alejandro sobre Persia y el fin del imperio alrededor del 330 a. C. (Waters, 2014). 
asimismo una comunicación directa con el lector y una efectiva transmisión del mensaje. Por lo cual, para Fernández Retamar, en este tipo de poesía existe "un acercamiento [...] entre verso y conversación" (1995, p. 173).

Según los elementos deícticos de persona, lugar y tiempo en "Le preguntaron...", el yo poético de la instancia de enunciación es un ateniense del siglo V a. C. (alrededor del 490 y el 479) que habla desde Grecia. Fernández Retamar establece la instancia de lugar de enunciación del ateniense en un momento preciso de la historia griega, pues el ateniense habla de la "decisión profunda de quedar siempre en esta tierra en que nacimos" (2009, p. 209), o sea, Grecia. Y en los últimos versos del poema, anuncia que dará una ofrenda a los dioses "frente a la isla de Salamina" (2009, p. 209), donde Persia perdió una batalla naval. "Le preguntaron..." consiste en un poema de circunstancia que vigila el presente, un poema testimonio de la coyuntura social y política en el hemisferio americano durante la década de los sesenta del siglo XX. La victoria griega en Salamina establece una figuración del triunfo cubano en Girón en 1961.

Siguiendo la alegoría de "Le preguntaron...", Estados Unidos está compuesto por un amplio territorio de grandes lagos y campos, cuyas costas están junto a los mares Atlántico, Caribe y Pacífico, a semejanza de la expansión territorial persa. Además, "Los persas son potentes y grandes: cuando ellos / se estremecen, hay un hondo temblor, un temblor / que recorre las vértebras del mundo. Llevan por todas partes sus carros ruidosos y / nuevos, sus tropas intercambiables, sus barcos/ atestados cuyos velámenes hemos visto en el / horizonte" (Fernández Retamar, 2009, p. 208)3․ Fernández Retamar no duda en hacer explícita la intertextualidad de este texto con el poema "A Roosevelt" de Darío, quien dijo en 1904, aproximadamente cincuenta años antes: "Los Estados Unidos son potentes y grandes. / Cuando ellos se estremecen hay un hondo temblor / que pasa por las vértebras enormes de los Andes" (1977, p. 255). Fernández Retamar retoma esta advertencia para componer su texto; haré una comparación detallada de estos poemas más adelante.

Los versos que siguen describen la Antigua Grecia ${ }^{4}$ en analogía al Caribe y América Latina: "Pesan como un fardo sobre la salpicadura de / nuestras poblaciones pintorescas y vivaces / Echadas junto al mar" (Fernández Retamar, 2009, p. 209). Al considerar que el yo poético es un ateniense, entonces, Cuba, como una de las islas mayores del Caribe, es comparada con Atenas, situada en la Grecia peninsular; la salpicadura de las demás poblaciones corresponde a la región insular del Caribe; y la Grecia continental representa a las regiones continentales de América. Por eso, el ateniense declara: "Sabemos que no sólo nosotros, estos pocos rodeados / de un agua enorme" (2009, pp. 208-209). Aquellos “otros" son los habitantes de la Grecia continental, o sea, la América Latina. En 1974, Fernández Retamar hace explícita esta comparación poética previa al referirse a América Latina y al Caribe con las expresiones "países continentales" y "países antillanos": "Tanto los países continentales, desde México hasta Chile y la Argentina, como los países antillanos, formamos parte de una comunidad mayor, en desarrollo, que Martí llamó 'Nuestra América', para distinguirla de la América que no es nuestra, a la que llamó 'la América europea': los Estados Unidos” (1982, p. 187). La fraternidad e identidad regional se manifiesta

3 De acuerdo con Herodoto, los griegos solían sobrecogerse al escuchar la palabra medos (persas) (1974). La marcha de sus ejércitos podía aún hacer temblar la tierra (Holland, 2007).

4 La Antigua Grecia o Hélade comprendía diversos territorios, una región insular de varias islas y archipiélagos y dos regiones continentales formadas por la península Balcánica y las zonas de la costa del Asia menor. 
previamente en poemas como "Le preguntaron..." o "Carta a Juan Gelman", "Carta a Roque Dalton" de Sí a la Revolución, en los cuales comunica inquietudes y anhelos, en la búsqueda por forjar una hermandad cultural caribeña y americana, como en "Allá lejos" (Nicaragua) o "Mi hija mayor va a Buenos Aires" de Aquí (1990-1999).

Y así como fue necesaria la unidad entre las polis griegas, Fernández Retamar concibe a los países del Caribe y América Latina -como estados diversos de "poblaciones pintorescas y vivaces" (2009, p. 209) - no solamente como una unidad geográfica, sino como una unidad histórica y cultural desde la resistencia anticolonial del siglo XVI. Si el Caribe "es una unidad histórica desde que llegó a sus aguas Cristóbal Colón” (Bosch, 2009, p. 758), esta unidad histórica se aplica también a los países continentales. Tras el triunfo de la Revolución Cubana, Fernández Retamar afirma que para muchos ser "cubanos implica un orgullo, una vocación”; sin embargo:

nuestra órbita histórica inmediata -sean cuales fueren las apariencias- es Hispanoamérica: en sus bordes es que damos la batalla por nuestra sobrevivencia; nos injertamos en el mundo gracias a esa articulación. [...] Intentar resolver nuestros problemas sólo en el área ceñida del país es -quizá por desdicha-imposible: somos parte, pedazo de conglomerados más vastos. El primero de ellos, aquel que ya sí es un todo, Hispanoamérica (2004, p. 37).

Esta conciencia de integración y soberanía regional aparece previamente en Martí, para quien los países hispanoamericanos forman una patria y Cuba se complementa en esta. En la introducción de sus Versos sencillos (1891), explica que aquellos versos nacieron cuando los pueblos hispanoamericanos "se reunieron en Washington", bajo el "águila temible", "el águila de López y de Walker" (filibusteros en Cuba y Nicaragua), que pretendían apartar a Cuba "para bien único de un nuevo amo disimulado, de la patria que la reclama y en ella se completa, de la patria hispanoamericana" (Martí, 1978, p. 23). Asegura, además, que todo lo que hizo por la independencia de Cuba fue para impedir la vulneración de la soberanía regional (como se citó en Fernández Retamar, 2007, p. 238). Por eso se ha dicho que Martí es "la fuente más importante del pensamiento anti-colonial” de Fernández Retamar (Machín, 2000, p. 159).

En "Le preguntaron...", la pertenencia e identificación territorial de los cubanos se compara a la de los griegos ${ }^{5}$, pues considera "la tierra dura y arbolada, enteramente / nuestra" (Fernández Retamar, 2009, p. 209). Esta actitud en el poema permite, asimismo, el papel gravitacional de los griegos en la historia europea para aplicarlo a la historia americana. El ateniense declara que, debido a la resistencia griega, ellos contarán en el futuro "cómo el frágil hombre [...] pudo vencer" a una potencia como Persia, o bien, "para que otros cuenten, sobre nuestra huesa convertida / en cimiento" (Fernández Retamar, 2009, p. 209). Debido a la desigualdad militar entre Grecia y Persia, el triunfo griego en varias batallas fue sorprendente, esto estableció un fundamento para el futuro, ya que el "relato de cómo se habían enfrentado a una superpotencia y la habían derrotado parecía la historia más extraordinaria de todos los tiempos" (Holland, 2007, p. 19); principalmente: "Si los griegos hubiesen sucumbido ante la invasión de Jerjes, Occidente no sólo

5 Conforme a Holland, "entre los griegos, el arraigo profundo a la tierra era una fuente de prestigio" por no haber permitido que un invasor la haya conquistado y por haber preservado así su cultura y libertad (2007, p. 147). En el discurso del funeral de Pericles, quien hizo reconstruir Atenas después de las guerras con Persia, se lee: "El mismo tronco étnico, generación tras generación, y el mismo pueblo han vivido siempre en ésta, nuestra tierra nativa; y es este pueblo el que, en virtud de sus méritos, nos ha legado un país eternamente libre". Holland explica que, al recorrer su territorio, los atenienses "se sabían parte del paisaje", lo que formó una identidad regional única (2007, pp. 147-148). 
hubiese perdido su primera lucha por la independencia y por la supervivencia, sino que nunca habría existido una entidad llamada 'Occidente"' (Holland, 2007, p. 20). Para la historiografía europea, si Grecia hubiera perdido su libertad, habría sido un desastre para el resto de Europa (Burn, 1963). Fernández Retamar concibe así, poéticamente, antes de sus principales ensayos, el papel de Cuba en relación con el Caribe y América Latina, de forma semejante a la función que tuvo Grecia con respecto a Europa.

Este aspecto gravitacional de Cuba en el poema recuerda a Martí, quien declaró sobre su lucha por la independencia de su patria y la humanidad: "Es un mundo lo que estamos equilibrando: no son sólo dos islas [Cuba y Puerto Rico] las que vamos a libertar". Luego dice: "Un error en Cuba, es un error en América, es un error en la humanidad moderna. Quien se levanta hoy con Cuba se levanta para todos los tiempos" (como se citó en Fernández Retamar, 2007, pp. 238-239). Tras la Revolución Cubana, nuevamente se habla de la actuación preponderante de Cuba en la historia contemporánea: "La batalla de Cuba había terminado, y con su final comenzaba en el Caribe una nueva época histórica” (Bosch, 2009, p. 758). Si bien Fernández Retamar tiene un alto compromiso con su nación, lo hace pensando en la humanidad y, parafraseando a su maestro absoluto, declara: "así, cuando digo patria digo humanidad. Es aquella parte de la humanidad donde me tocó vivir y cumplir con mi deber" (como se citó en Marras, 1992, p. 331) ${ }^{6}$.

Desde la poesía, Fernández Retamar reflexiona la relación entre Cuba con los Estados Unidos, porque asegura que se "requieren [conocer] al menos dos siglos" (2004, p. 211) para comprender el diferendo cubano-estadounidense y medir "con justicia nuestra historia" (2004, p. 214), pues "cuando el pasado es incierto, el futuro es impredecible" (2004, pp. 224-225).

\subsection{Continuidad cultural}

En "Le preguntaron...", Fernández Retamar cavila con respecto a la importancia de la palabra, la conversación y la preservación del pensamiento caribeño y latinoamericano. El ateniense expresa:

\footnotetext{
Aprendiendo unos de otros en la conversación de

la plaza pública el lujo necesario de la verdad que salta del diálogo,

y conocedores de que las cosas todas tienen un orden, y ha sido dado al hombre el privilegio de descubrirlo y exponerlo por la sorprendente palabra (2009, p. 209) 7 .
}

Fernández Retamar entiende que el pensamiento y la palabra propician el descubrimiento de la verdad, o sea, el orden de los elementos de la vida: "Es que pensar es estructurar la

$6 \quad$ Martí declaró en 1895: "Patria es humanidad, es aquella porción de la humanidad que vemos más de cerca y en que nos tocó nacer; y ni se ha de permitir que con el engaño del santo nombre se defienda a monarquías inútiles, religiones ventrudas o políticas descaradas y hambronas, ni porque a estos pecados se dé a menudo el nombre de patria, ha de negarse el hombre a cumplir su deber de humanidad, en la porción de ella que tiene más cerca. Esto es luz y del Sol no se sale. Patria es eso" (1973, p. 468).

$7 \quad$ Holland describe la costumbre en Atenas del debate público en asamblea abierto para todos los ciudadanos atenienses sin distinción de clases. Atenas era "una ciudad en la que la vida política ya no estaba circunscrita a los recargados y exclusivos salones de la aristocracia, sino que se debatía públicamente en la asamblea" (2007, p. 185). 
realidad" (como se citó en Marras, 1992, p. 308). De acuerdo con él, la poesía "contempla o conforma" la vida humana: “¿De qué "vida' hablamos que pueda ser concebida con prescindencia de la poesía? No, ciertamente, de la vida humana” (Fernández Retamar, 2007, p. 109), ya que considera que descubrir el orden de la realidad no está reservado a un grupo exclusivo, sino que este conocimiento se revela a través de la "conversación" pública, pues el diálogo posee una dinámica de correspondencia enriquecedora. Concibe que la verdad puede ser tratada en la poesía conversacional, ya que "suele señalar la sorpresa o el misterio de lo cotidiano" (Fernández Retamar, 1995, p. 126). Se pregunta si la realidad resulta en caos o cosmos, y opta por lo segundo:

\footnotetext{
considero a la poesía una de las vías que nos permiten revelar el sentido sagrado de la realidad. Al igual que Martí, mi maestro de siempre, tengo la certidumbre de que en el presunto caos hay un orden secreto, un cosmos (Fernández Retamar, 2000, pp. 165-166).
}

Siguiendo lo dicho y conforme a este poema, el conocimiento concreto de la realidad del Caribe y América Latina ha sido indagado y expuesto por figuras históricas:

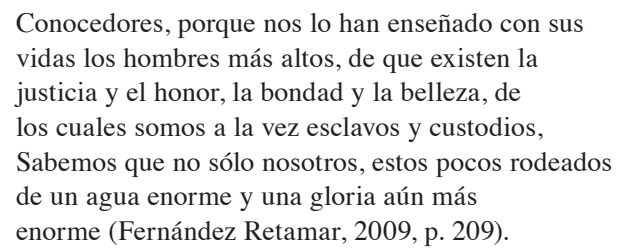

A pesar de no haber una referencia explícita en el poema, según lo descrito hasta ahora, para Fernández Retamar, José Martí constituye uno de aquellos "hombres más altos", pues para él, Martí se establece como una figura mundial, además de cubana (como se citó en Alemany, 1997, p. 211). Lo considera "el hombre más extraordinario que haya existido, para decirlo de una manera brutal” (como se citó en Benedetti, 1972, p. 211).

En el poema, el ateniense exclama con una voz colectiva: "somos a la vez esclavos y custodios" de los valores y el pensamiento de "los hombres más altos". Fernández Retamar elabora su razonar poético e intelectual mediante el estudio de la tradición intelectual caribeña y latinoamericana, es un esclavo (crítico) y custodio, retoma siempre las ideas de personalidades como Martí, Darío, y otros, para tener un pensamiento con una perspectiva americana propia. Por ejemplo, aclara que, sin desconocer aportes de pensadores de otras partes del mundo, su ensayo Calibán "se escribió, como es claro, desde puntos de vista de nuestra América, desde puntos de vista que se remiten en primerísimo lugar a Martí, mi maestro absoluto, y también a Bolívar, a Ortiz, a Mariátegui, a Martínez Estrada”, etc. (Fernández Retamar, 2005, p. 94).

Al ser esclavos críticos y custodios de la tradición intelectual, de acuerdo con Fernández Retamar, elaboramos y transmitimos un pensamiento diferenciado, con valores propios, preservamos una prolongación cultural continental propia:

Creo que en países como los nuestros, la continuidad cultural (una continuidad crítica, por supuesto) está vinculada a nuestra misma sobrevivencia como pueblo, y quizás ello explique el interés que para mí ha tenido el trabajo intelectual cubano o hispanoamericano anterior (como se citó en Benedetti, 1972, p. 204).

De esta forma, sostiene indudablemente que nuestra América posee una "unidad espiritual" (como se citó en Alemany, 1997, p. 214). Estudiar el pensamiento de Fernández Retamar permite rescatar "un modelo de reapropiación -activa, estricta y sin concesiones- 
de la tradición continental" (Moraña, 2002, p. 564), actitud expresa primeramente en su poesía. Preservar críticamente el pensamiento caribeño y latinoamericano exige recuperar a quienes tuvieron una reflexión descolonizadora: "tenemos que volvernos efectivamente a los hombres y mujeres nuestros que en su conducta y en su pensamiento han encarnado e iluminado esta actitud" (Fernández Retamar, 2005, p. 55).

Cuando Fernández Retamar habla de la importancia de recuperar el pensamiento crítico de la región, considera también a quienes reflexionan desde más allá del Caribe y América Latina. Martí fue el primero de estos, pues escribió desde los Estados Unidos, “donde llegó a tener un conocimiento profundo de la realidad" de aquel país (Fernández Retamar, 1995, pp. 304-305), en el cual fue "promoviéndose como intermediario entre los Estados Unidos y varios grupos latinoamericanos" (Ramos, 2009, p. 176).

\section{Rubén Darío, padre del idioma}

Uno de aquellos "hombres más altos" es también Rubén Darío. "Le preguntaron..." está dedicado al poeta nicaragüense, conserva una relación intertextual explícita con "A Roosevelt" y "Los cisnes" y trata temas semejantes que inquietaron a Darío. Además, el poema de Fernández Retamar asume la tradición poética modernista, ya que guarda características estilísticas propias del aquel movimiento.

\subsection{Le preguntaron por Roosevelt}

"Le preguntaron...” y “A Roosevelt" tienen estructuras similares. Ambos están en primera persona. Y así como el nicaragüense describe a los Estados Unidos / Roosevelt en las primeras estrofas y luego a su América, de igual modo, el cubano describe primeramente a los persas y luego a los griegos. Recurren a la historia de manera cosmopolita para hablar críticamente acerca de sus respectivas épocas separadas por poco más de medio siglo. Darío recurre a la antigua historia de Grecia y Mesopotamia; Fernández Retamar retoma la historia de Grecia y de Persia, utilizando un recurso modernista, el cosmopolitismo, para reflexionar sobre su historicidad. Ambos identifican a su América con elementos griegos y a los Estados Unidos con características asiáticas.

El yo poético de "A Roosevelt" enuncia desde un tiempo histórico moderno, a comienzos del siglo XX; en "Le preguntaron...", el hablante lírico es un ateniense del siglo V a. C.. Darío describe a Roosevelt / Estados Unidos con admiración, temor y cierta resignación ante la fortaleza y el destino de aquella nación. Fernández Retamar, por el contrario, escribe su poema con un tono de resuelta entereza, confianza y certidumbre por la determinación de la defensa de Grecia / Cuba y las regiones circundantes. Roosevelt resulta "primitivo y moderno, sencillo y complicado", posee tres porciones de la "fácil conquista" de Nemrod, el "culto de Hércules [y] el culto de Mammón" mientras "la Libertad levanta su antorcha en Nueva York" (Darío, 1977, pp. 255-256). Si bien Darío reconoce en el poema valores estadounidenses, el yo poético de "Le preguntaron..." no identifica en Persia (Estados Unidos) ninguno, debido a la circunstancia bélica que le aqueja.

De acuerdo con Fernández Retamar (1983), la administración estadounidense ha sido el mayor infractor de la soberanía de los pueblos en Nuestra América, crítica dirigida a la política de sus gobernantes y no a la población. A pesar de la afrenta, siempre ha expresado 
su admiración y estima por esta nación: "Los Estados Unidos son un país extremadamente complejo, que conozco muy bien, que quiero mucho" (como se citó en Marras, 1992, pp. 315-316). Entiende que el legado de este país consiste en la valiente defensa de la democracia de la Declaración de la Independencia y el valor de quienes ayudaron a derrotar el nazismo (Fernández Retamar, 1983, p. 194), pues ha exclamado: "Uno de los grandes textos en la historia de la humanidad es la declaración de la independencia norteamericana según la cual todo hombre nace libre" (como se citó en Marras, 1992, p. 308). Por eso, el poeta ha dicho: "Yo creo en el panamericanismo", pero uno de "manera armónica", sin hegemonía; porque, como en la música, somos con los Estados Unidos "una unidad cultural y en ese sentido ya estamos unidos” (como se citó en Marras, 1992, pp. 314-315).

Con impronta modernista (cosmopolita), Darío y Fernández Retamar llaman al agresor "bárbaro". El ateniense de "Le preguntaron..." utiliza la frase "bárbaro graznador" en un sentido cultural porque así lo exige el contexto histórico del hablante poético, o sea, la Grecia del siglo V a. C., en el cual se llamaba bárbaros a los pueblos cuyas lenguas eran incompresibles, como el sonido desigual y disonante del graznido de algunas aves. Darío por su parte escribe: "hombres de ojos sajones y alma bárbara”. Con "sajón”, el poeta describe una parte del pueblo germánico que se implantó en Inglaterra durante el siglo V d. C. Los romanos tomaron el término "bárbaro" de los griegos para nombrar a los sajones, entre otros, por considerarlos inferiores. Ambos poetas utilizan el término "bárbaro" en el sentido en el que, posterior a la civilización romana, Europa occidental se refería a aquellas culturas distintas a esta, las cuales no eran "civilizadas" según sus criterios.

Darío refiere con persistencia la etnicidad de la población del continente americano. Al hablar de los aspectos indígenas y españoles en América, menciona la diversidad ancestral de la región y al mestizaje étnico y cultural. En cambio, cuando Fernández Retamar alude a toda Grecia como "la salpicadura de / nuestras poblaciones pintorescas y vivaces", habla solamente de la diversidad o el mestizaje cultural del Caribe y América Latina, y no así de un mestizaje étnico. En sus ensayos posteriores, utiliza el término mestizaje en un sentido cultural y no étnico, concepción que le "es completamente ajena e inaceptable" (Fernández Retamar, 2000, p. 94).

El fervor de Darío se mantiene enérgico: "Tened cuidado", “[s]e necesitaría, Roosevelt, ser Dios mismo, / el Riflero terrible y el fuerte Cazador, / para poder tenernos en vuestras férreas garras" (1977, p. 256). Esta postura briosa de Darío había sido alimentada por la advertencia de Martí con respecto a la patria de Roosevelt, pues el nicaragüense dijo en 1898: "Sólo una alma ha sido tan previsora sobre este concepto, tan previsora y persistente [...] la del padre de Cuba libre, la de José Martí” (Darío, 1983, pp. 85-86). De acuerdo con Paz (1964), los modernistas tuvieron conciencia de una identidad americana, más allá de las fronteras nacionales. Varios escribieron en defensa de "nuestra civilización": "Con ellos aparece el anti-imperialismo", pero "[s]u anti-imperialismo no es político ni ideológico" (Paz, 1964, p. 12). Según Paz, Darío percibe que, entre la América hispana y la América anglosajona, existe un conflicto de dos distintas "entidades históricas" con su propio "temple" y "genio", con "maneras de ver y sentir diferentes", y cada cual con "una tradición y una sensibilidad" particulares (1964, p. 12). En este sentido, para Rama, el modernismo expresa las diversas formas de la:

[...] incorporación de América Latina a la modernidad, concepción sociocultural generada por la civilización industrial de la burguesía del XIX, a la que fue asociada rápida y violentamente nuestra América en el último tercio del siglo pasado, por la expansión económica y política de los imperios europeos a la que se suman los Estados Unidos (Rama, 1974, p. 129). 
Fernández Retamar asume en sus versos la tradición cultural literaria transmitida por los modernistas que aboga por la soberanía de las naciones americanas. La intervención continua en la región "habría de convertirse en la experiencia histórica decisiva de estos hombres [...], el modernismo, sin abandonar lo mejor de sus conquistas formales, cambia de signo. Así nace la literatura del siglo XX latinoamericano" (Fernández Retamar, 1995, p. 219). Esta actitud anticolonial constituye parte de la identidad de su América: "nuestra cultura es -y solo puede ser- hija de la revolución, de nuestro multisecular rechazo a todos los colonialismos; nuestra cultura, al igual que toda cultura, requiere como primera condición nuestra propia existencia" (Fernández Retamar, 2005, p. 80).

Darío y Fernández Retamar recurren a la historia antigua de Asia y Grecia para configurar un léxico modernista como una herramienta de comparación histórica y crítica. "Le preguntaron..." se constituye como un poema histórico que permite la homologación entre el pasado y el presente, puesto que el pasado se nos presenta como un hecho actual. En algunos poemas de Fernández Retamar "[e]l pasado y el presente tienden a confundirse como si fuesen un tiempo único" (Gonzales, 2009, p. 16).

\section{2 “R.D.", Zeus del idioma}

En "Le preguntaron...", el idioma griego / castellano deriva en lengua vehicular y de resistencia cultural de la región ante la expansión del territorio y la lengua persa / inglés. El ateniense exclama: "no sólo" los habitantes de la isla "[s]ino tantos millones de hombres, no hablaremos ese / idioma que no es el nuestro, que no puede ser / el nuestro" (Fernández Retamar, 2009, p. 209). Esta declaración contundente responde a una razón histórica que requiere explicación.

En América, el castellano es fundamental para la identidad y unidad hispanoamericana. Sin embargo, para haber alcanzado esta cualidad, la sociedad hispanoamericana tuvo que experimentar un complejo proceso histórico de implantación, castellanización y apropiación del idioma. Durante el coloniaje español, "la lengua fue compañera del imperio" (Nebrija, 1926, p. 3). La implantación del castellano no tuvo gran oposición en algunas regiones como en el Caribe donde los habitantes taínos y siboney fueron exterminados junto a sus lenguas. Pero en otras regiones, como la mesoamericana o sudamericana, donde se hablan aún diversos idiomas, las sociedades milenarias de América sufrieron un proceso de castellanización hasta el presente. Por siglos, el castellano -también el portugués- se convirtió en una herramienta de dominio hegemónico, intelectual, cultural y económico de la élite criolla y mestiza en detrimento de los hablantes de idiomas originarios ${ }^{8}$. A la postre, el castellano es apropiado en América para discrepar con el colonizador, como una forma de resistencia. Esto implica, para Fernández Retamar, asimilar sus mecanismos conceptuales, puesto que para argüir y refutar

$8 \quad$ Al considerar la numerosa población de "los habitantes originarios de América" en países como México, Guatemala, Perú o Bolivia, entre otros, Fernández Retamar afirma que el castellano y portugués "no son las lenguas de millones de 'iberoamericanos' que ni saben qué significa esa palabra (tampoco 'latinoamericanos'), y a quienes se les pretende imponer a sangre y fuego otra civilización (¿la nuestra?: en todo caso no será la mía), que es lo mismo que intentaron los conquistadores” (2005, p. 96). A esta experiencia indígena se suma la experiencia de la diversa población africana esclavizada con características culturales y lingüísticas variadas que experimentó un proceso complejo en la asimilación del idioma del esclavizador. 
con el colonizador había que hacerlo en su lengua: “¿de qué otra manera puedo hacerlo, sino en una de sus lenguas, que es ya también nuestra lengua, y con tantos de sus instrumentos conceptuales, que también son ya nuestros instrumentos conceptuales?" (2005, p. 36).

El resguardo decidido del castellano en "Le preguntaron...", tiene posteriormente su correspondencia ensayística. Fernández Retamar explica que, a pesar de la gran diversidad idiomática, "nuestro idioma es el español, el castellano", el cual permite "una comunicación uniforme" para comprenderse, pues: “Cómo van a entenderse, en nuestra América, los descendientes de azteca con los de mandinga y los de vasco, sino en castellano?” (2007, p. 123). Y concluye:

\footnotetext{
la lengua del conquistador es una lingua franca. No es sólo un instrumento de dominio, ni es desde luego en calidad de tal como permanece en la colonia de ayer. Creada por todo un pueblo, es aceptada y recreada por nuevos pueblos (2007, p. 133).
}

En el poema "Patria" de Sí a la Revolución, ya había considerado este tema cuando dijo lo siguiente sobre Cuba: "Eres la lengua para comprendernos" (Fernández Retamar, 2009, p. 155).

El castellano se formó hace unos mil años y, según Luisa Campuzano, en palabras de Fernández Retamar, la "mitad de ese milenio ha visto crecer al español en ambas márgenes del Atlántico" (1995, p. 339). El poeta observa que las grandes obras literarias españolas conocidas como el siglo de oro aparecieron después de 1492 y "hay que insistir en que ese oro verbal fue hijo también del oro de nuestras minas, arrancado de las entrañas de un continente martirizado" (1995, p. 339). En este sentido, los valores paradigmáticos tradicionales del término "castellano" ("Natural de Castilla", "Región de España", "Lengua española", "Variedad de la lengua española") son ampliados en América. El castellano, además de ser lengua vehicular, es asimismo lengua vernácula de América. Por eso, sostengo que hacer del castellano un idioma propio de América significa ejercer la facultad de disponer de este idioma; concebirlo como una característica peculiar, natural del continente americano, y no meramente postiza ni artificial.

Asimismo, "Le preguntaron..." mantiene una relación intertextual con el poema "Los cisnes" de Darío, donde el nicaragüense interpela afligido por el futuro del castellano: “¿Seremos entregados a los bárbaros fieros? / ¿Tantos millones de hombres hablaremos inglés? / ¿Ya no hay nobles hidalgos ni bravos caballeros? / ¿Callaremos ahora para llorar después?" (1977, p. 263). Darío se expresa de manera colectiva y manifiesta incertidumbre por el futuro de la región. Al considerar las circunstancias históricas de su época -intervención estadounidense en Cuba y Puerto Rico (1898), Colombia (1904), Nicaragua (1909), Haití (1915), República Dominicana (1916), en el mismo año de su muerte- la preocupación de Darío por la hegemonía del inglés en la región hispanoamericana se debe también a la situación que atraviesa Puerto Rico luego de la ocupación estadounidense, donde de repente se establece al inglés como idioma oficial, junto con el español. Por eso, el castellano "hoy por hoy es una lengua de resistencia", pues en Cuba y Puerto Rico "puede considerarse no solamente la lengua de la memoria hegemónica (y subalterna), sino lengua de resistencia" (Lemaître, 2002, p. 620). Darío demanda en sus versos el pronunciamiento de la gente en relación con este asunto y alerta acerca de las consecuencias de mantenerse en silencio. Seis décadas después, al ver afrentada la soberanía de su patria, ante la pregunta de Darío “¿Tantos millones de hombres hablaremos inglés?" (1977, p. 263), Fernández Retamar responde: "tantos millones de hombres, no hablaremos ese / idioma que no es el nuestro" (2009, p. 209). El cubano no calla, responde 
valientemente y con certidumbre, como custodio de los valores culturales de la región y continuador crítico del pensamiento hispanoamericano.

La defensa del castellano no objeta el aprendizaje de otros idiomas, por el contrario, el multilingüismo siempre ha distinguido a los americanos, el Inca Garcilaso de la Vega, por ejemplo, conocía quechua, latín, italiano y otros; Sor Juana Inés de la Cruz, náhuat y latín. El cosmopolitismo, por su parte, caracteriza a poetas modernistas y vanguardistas: el excepcional Tamayo (Bolivia) sabía más de ocho idiomas; Gutiérrez Nájera (México) y Gómez Carrillo (Guatemala) dominaban el francés; Henríquez Hureña (República Dominicana), De la Selva (Nicaragua) y Novo (México), el inglés. Martí visitó Francia y vivió en Nueva York; se cultivó de varias literaturas; escribía en español, francés e inglés (Fernández Retamar, 1995). Fernández Retamar estudió en París y Londres, enseñó en la Universidad de Yale; labró su conocimiento poético en la lengua de poetas franceses e ingleses. Sin embargo, como diría Martí: "Injértese en nuestras repúblicas el mundo; pero el tronco ha de ser el de nuestras repúblicas" (Martí, 2005, p. 34), y la permanencia de la cultura de una sociedad dependerá en explicar su realidad en su propia lengua:

Si queremos pensar, vislumbrar siquiera el universo, tenemos que hacerlo a través del lenguaje; en nuestro caso, a través del español. La palabra es nuestra morada, en ella nacimos y en ella moriremos, ella nos reúne y nos da conciencia de lo que somos y de nuestra historia (Paz, 1997, p. 33).

Darío no hubiera tenido aquella postura franca y soberana con respecto al castellano si no hubiera experimentado un cambio en su identidad cultural. Después de haber experimentado una vida cosmopolita, la preocupación de Darío por su América surge algunos años antes de escribir "Los cisnes". Fernández Retamar expresa esta situación en el poema "R.D." (Rubén Darío) de Que veremos arder (1966-1969), donde habla de su cosmopolitismo, su interés por Francia y su reconciliación con España y América. El poema expresa: "Descubrió que nacer en Nicaragua no era (como / se aseguraba) una insalvable limitación / Y se fue a Chile / Donde suspiró por Francia / Hasta que en un café del Quartier Latin encontró / a su Verlaine", quien le profirió una grosería (2009, p. 234). El poema "R.D." describe los viajes que Darío realizó por varios países americanos y a París. En su autobiografía, revela que soñaba desde niño con conocer París, ciudad que le parecía un paraíso. A pesar de su ilusión, confiesa que "[a]penas hablaba una que otra palabra de francés" (Darío, 1916, pp. 147-148). De ahí que, para Fernández Retamar, la primera etapa del modernismo "tuvo su poesía de cartón piedra grecolatina o ajaponada (favorecida por el hecho de que sus autores no conocían a Grecia o a Japón sino por el forro de algunos libros franceses)" (2000, p. 73).

Asimismo, los versos refieren al decepcionante encuentro que Darío tiene con el bardo francés Paul Verlaine (1844-1996) en un café. Según el nicaragüense, el poeta galo bebía abundantemente mientras golpeaba la mesa. Al ser presentado, recuerda Darío:

Yo murmuré en mal francés toda la devoción que me fue posible, concluí con la palabra gloria... Quién sabe qué habría pasado esta tarde al desventurado maestro; el caso es que, volviéndose a mí, y sin cesar de golpear la mesa, me dijo en voz baja y pectoral: 'La gloire!...La gloire!...M....M. encore!...' (1916, pp. 148-149).

Darío buscó a Verlaine en otras oportunidades, pero siempre lo encontraba en el mismo estado etílico. Y describe con angustia esta experiencia: "aquello, en verdad, era triste, doloroso, grotesco y trágico" (1916, p. 149). Darío contrasta en sus memorias la admiración por París con el decepcionante encuentro con Verlaine, a pesar de su devoción por aquella ciudad, no esconde su desencanto. Con respecto a la estancia de Darío en Europa, Paz asegura: "la experiencia 
europea le reveló la soledad histórica de Hispanoamérica" y reconoció en Europa "un mundo indiferente o desdeñoso de lo nuestro" (1964, p. 12).

Fernández Retamar alude en el poema al cosmopolitismo de Darío y seguidamente sostiene que el nicaragüense "[s]e reconcilió con el idioma, con España, con / América. / Volvió a Nicaragua, y verificó que sólo la muerte es / limitación” (2009, p. 234). Según el mismo Darío, luego de su permanencia en París, reside en Buenos Aires, después se dirige a España en 1898 para escribir acerca de las condiciones de España luego de la guerra con los Estados Unidos y la perdida de sus últimas colonias. Según Paz, la experiencia en Europa "lo hicieron volver los ojos hacia España. Ve en ella algo más que el pasado; un principio todavía vigente y que da unidad a nuestra dispersión" (1964, p. 12). Este cambio de Darío se manifiesta en su poesía y, al comparar el primer periodo modernista con el segundo, Fernández Retamar observa: "dos mundos distintos: superficial y falso el uno, profundo y veraz el otro" (2000, p. 50). La reconciliación de Darío con América y España deja una decisiva actitud a favor de su idioma e identidad, hace un llamado a la unidad y enaltece el carácter hispánico como se verifica en el poema "Salutación del optimista" de Cantos de vida y esperanza (1905) donde insta: "Únanse, brillen, sacúndense, tantos vigores dispersos; / formen todos un solo haz de energía ecuménica" (1977, p. 248).

Al concluir "Le preguntaron...”, Fernández Retamar enaltece a Darío y a la herencia cultural escrita en Hispanoamérica: "Y escribimos nuestra protesta -ioh padre del / idioma!en las alas de las grandes aves que un / día dieron cuerpo a Zeus" (2009, p. 209). Estos versos requieren ser desmetaforizados, para lo cual se debe recurrir a la intertextualidad implícita y a otros textos de Fernández Retamar. En diversas ocasiones, llama a Darío "el padre de la poesía en lengua castellana de este siglo" (Gordon, 1992, p. 683; como se citó en Marras, 1992, p. 315) y "padre y maestro mágico" (Fernández Retamar, 1995, p. 340). El origen de la frase "padre y maestro mágico" se encuentra igualmente en un poema de Darío dedicado a Verlaine llamado "Responso" (1977, p. 218). Para Dapaz, este poema de Darío, además de ser un tributo a Verlaine, es una reflexión de la muerte, la "magia de las palabras y la omnipotencia del pensamiento" (1987, p. 188).

En estos versos Fernández Retamar se refiere, igualmente, a un motivo de la mitología griega, en la ocasión en que Zeus toma la forma de un cisne para allegarse a Leda; con esto alude a Darío y a su poesía, ya que la figura del cisne se instaura en parte importante del sistema simbólico de sus poemas. La expresión "Zeus" significa entre los antiguos griegos "dios" o "padre" de los hombres y dioses, como principales acepciones. Si para Fernández Retamar Darío se erige como el "padre del idioma", entonces, en el poema, "Zeus" se instaura en una representación de Darío. Esto nuevamente me lleva a considerar lo siguiente. En "Responso" de Darío, el poeta "quiere que se le honre como a un dios y que se le ofrezcan libaciones y ofrendas" (Dapaz, 1987, p. 196). Los valores de "inmortal" e "imperecedero" derivados del término "Zeus" pueden igualmente aplicarse a Darío, iniciador de la renovación de la poesía en castellano y figura permanente de la modernidad literaria.

Cuando personifica a Darío como Zeus, Fernández Retamar también representa en el poema al idioma como un dios. Al tomar los valores semióticos de "Zeus" ("dios" y "padre") y al desplazarlos al campo semiológico, distinguimos valores como "inmortal" y "protector", de esta forma, asigna al idioma la cualidad de imperecedero y lo distingue como guardián. De hecho, con anterioridad, en "Bienaventuranza del idioma" de Alabanzas, Conversaciones (19511955), Fernández Retamar ya había personificado al idioma como un dios padre -además de 
considerarlo como un amigo, hermano e hijo- donde el idioma, figurado como alguien cercano, le es íntimo al poeta ya que lo siente dentro de sí mismo ("Sitio del corazón”)". Además, el idioma participa del difícil proceso de creación que surge de la propia vida y preserva la percepción del poeta para que no se disipe en el tiempo. "Bienaventuranza del idioma" consiste en una suerte de agradecimiento profundo por la existencia del idioma. Rostagno (1986) aclara que, en este poema, la "forma de la plegaria evangélica dirigida en este caso al todopoderoso idioma, al dios-idioma y sugerida por 'bienaventuranza' y el uso del apóstrofe lírico, imparte un valor sobrenatural y divino a la creación artística” (p. 45).

No extraña que años después de la publicación de "Bienaventuranza del idioma", Fernández Retamar considere en "Le preguntaron..." al idioma como un dios (Zeus), de tal forma que al escribir la protesta en "las alas de las grandes aves que un día dieron cuerpo a Zeus" (2009, p. 209) se refiere a escribir sobre las páginas de los libros que, como alas de grandes aves, sustentan y preservan aquello que consideramos grandioso e imperecedero mediante el idioma: el pensamiento de quienes nos antecedieron, como Darío, Martí y otros, con el cual se devela y conserva el conocimiento que tenemos de algunos aspectos de la vida y la realidad americana. La escritura y los libros se convierten en herramientas para preservar el idioma, la historia y la cultura, para mantener la continuidad cultural e intelectual de la región; razón por la cual, Fernández Retamar responde al llamado que Darío hizo en 1905 (“¿Ya no hay nobles hidalgos ni bravos caballeros? / ¿Callaremos ahora para llorar después?” [1977, p. 263]), y dedicará sus esfuerzos como custodio del idioma y el pensamiento heredado de las más altas mujeres y hombres de su América.

Como se ha expuesto, es evidente que la poesía de Fernández Retamar abriga conceptos fundamentales de reivindicación y asimilación de la herencia cultural cubana e hispanoamericana. Alumbra la ruta que seguirán sus ensayos, pues contiene la potencia que emana en el centauro de los géneros, y dilucida poéticamente el siglo anterior. Estos versos surgen de lo concreto de la sociedad cubana, el poeta tiene inicialmente una preocupación patriótica y después extiende su cavilación al resto de la región con temas como la historia, la soberanía y la continuidad cultural. "Le preguntaron por los persas", entre otros poemas, ejemplifica la postura de guardián crítico del saber intelectual regional, reconoce a Martí como su maestro absoluto y a Darío como padre moderno de la lengua. La exploración de este aspecto americanista de su poesía ha sido uno de los propósitos de este trabajo.

Fernández Retamar retoma de Martí la concepción de la función de la poesía, la literatura de circunstancia, conciencia histórica, cosmopolitismo y descolonización. En "Le preguntaron...", reitera la participación gravitacional de Cuba en la historia americana. Cuba como Atenas, Grecia a semejanza del Caribe y América Latina, y Persia en analogía a los Estados Unidos, son figuraciones metafóricas que permiten pensar en el presente histórico e imaginar formas culturales de convivencia.

Mediante la intertextualidad, Fernández Retamar rinde tributo a la trascendencia del pensamiento de Darío, asume su propia tradición poética y vindica del modernismo no solamente la renovación de la expresión sino también la condición descolonizadora. Considera a Darío

$9 \quad$ El poema dice: "Sitio del corazón, amigo que con serena mansedumbre / Recibes la caída del pecho, la diaria agonía, / El ruido de la vida, en el profundo vasto ámbito. / Hermano mejor, hijo mío, padre de estatura sin descanso, / Tú guardas el golpe y perseveras, y guardas / La caricia perdida entre las letras y el alarido" (Fernández Rematar, 2009, p. 73). 
como padre del idioma; destaca la importancia de la preservación del castellano como idioma de resistencia, lengua vehicular y vernácula en América; e insiste en la función del lenguaje y el diálogo para ordenar los elementos que componen la vida e intentar descifrar la verdad. De este modo, mujeres y hombres distinguidos registran los rasgos de la realidad americana y componen así una sucesión cultural que exige estudio y conservación. Y como esclavo crítico y protector de los valores heredados, Fernández Retamar se constituye en principal pensador y guardián de la soberanía cultural de la región.

\section{Bibliografía}

Alemany, B. (1997). Poética coloquial hispanoamericana. Alicante: Universidad de Alicante.

Arcos, J. (2001). Caliban, entre la nostalgia y la esperanza. Órbita de Roberto Fernández Retamar (pp. 7-28). La Habana: Unión.

Barquet, J. (2002). Para llegar a Aquí: paradoja, utopía y transtextualidad en Roberto Fernández Retamar. Revista de estudios hispánicos, 36(3), 579-602.

Benedetti, M. (1972). Los poetas comunicantes. Montevideo: Biblioteca de Marcha.

Bornstein, M. (1985). Roberto Fernández Retamar en la nueva poesía sociopolítica hispanoamericana. Revista de literatura cubana, 4, 106-131.

Bosch, J. (2009). De Cristobal Colón a Fidel Castro: El Caribe, frontera imperial. México: Fundación Juana Bosch.

Burn, A. R. (1963). Persia and the Greeks: The Defence of the West, 546-478 B.C. New York: St. Martin's Press.

Dalton, R. (1963). Con las mismas manos de Roberto Fernández Retamar. Casa de las Américas, 3(19), 56-57.

Dalton, R. (1967). Sobre Poesía reunida. Casa de las Américas, 7(41), 131-133.

Dapaz Strout, L. (1987). Un espacio sagrado en Prosas Profanas. En I. Schulman (Ed.), Nuevos asedios al modernismo (pp. 186-97). Madrid: Taurus.

Darío, R. (1916). La vida de Rubén Darío, escrita por el mismo. Barcelona: Maucci.

Darío, R. (1977). Poesía. Caracas: Biblioteca Ayacucho.

Darío, R. (1983). Prosas Políticas. Managua: Ministerio de Cultura.

Ellis, K. (1986). “YY Fernández?” in the Poetry of Roberto Fernández Retamar. Revista Canadiense de Estudios Hispánicos, 10(3), 353-373.

Fernández Moreno, C. (1982). Para América Latina, una poesía existencial. Casa de las Américas, 134, 28-39.

Fernández Retamar, R. (1982). Entrevisto. Ciudad de La Habana: Unión de Escritores y Artistas de Cuba.

Fernández Retamar, R. (1983). The Sovereignty of the Peoples: Challenges and Responses. Contemporary Marxism, 6, 193-204.

Fernández Retamar, R. (1995). Para una teoría de la literatura hispanoamericana. [Primera edición completa]. Santafé de Bogotá: Caro y Cuervo. 
Fernández Retamar, R. (2000). La Poesía, reino autónomo. Cuba: Letras Cubanas.

Fernández Retamar, R. (2004). Cuba Defendida. Buenos Aires: Nuestra América.

Fernández Retamar, R. (2005). Todo Caliban. Bogotá: ILSA.

Fernández Retamar, R. (2007). Antología Personal. México, D.F: Siglo XXI Editores.

Fernández Retamar, R. (2009). Poesía nuevamente reunida. La Habana: Letras Cubanas.

García, J. (1970). La poesía, la piadosa (Introducción y apuntes a un poema de Roberto Fernández Retamar). Cuadernos Hispanoamericanos, 241, 176-183.

Gonzales, C. (2008). La 'sequedad de documento,' o la poesía histórica retamariana. Hispania, 91(3), 590-599.

Gonzales, C. (2009). Retamar: Apuntes para la vida y obra de un Ariel en nuestra América. Lima: Universidad Nacional Mayor de San Marcos.

Gordon, S. (1992). Roberto Fernández Retamar: ensayo conversado. Revista Iberoamericana, 58(159), 675-90.

Heródoto. (1974). Los nueve libros de la historia. México: Porrúa.

Holland, T. (2007). Fuego persa: El primer imperio mundial y la batalla por occidente. Bogotá: Planeta.

Lazenby, J. (2007). The Defence of Greece, 490-479 B.C. Warminster, England: Aris \& Phillips.

Lemaître, M. (2002). La obra critica de Roberto Fernández Retamar. Revista de Estudios Hispánicos, 36(3), 603-626.

Machín, H. (2000). Roberto Fernández Retamar, profesional de la utopía. En E. Sklodowska y B. A. Heller (Coords.), Roberto Fernández Retamar y los Estudios Latinoamericanos (pp. 155-79). Pittsburgh, PA: Instituto Internacional de Literatura Iberoamericana, Universidad de Pittsburgh.

Marras, S. (1992). América latina. Marca Registrada. Buenos Aires: Grupo Editorial Zeta.

Martí, J. (1973). Obras Completas. La Habana: Editorial de Ciencias Sociales.

Martí, J. (1978). Obra Literaria. Caracas: Biblioteca Ayacucho.

Martí, J. (2005). Nuestra América. Caracas: Biblioteca Ayacucho.

Moraña, M. (2002). Introducción: La historicidad fermental de Roberto Fernández Retamar. Revista de estudios hispánicos, 36(3), 563-569.

Nebrija, A. (1926). Gramática de la lengua castellana: muestra de la istoria de las antiguedades de españa: reglas de orthographia en la lengua castellana. London y Nueva York: Humphrey Milford, Oxford University Press.

Paz, O. (1964). El caracol y la sirena. Revista de la Universidad de México, (4), 4-15.

Paz, O. (1997). Nuestra lengua. Casa Grande, 2(4), 32-33.

Rama, Á. (1974). Dialéctica de la modernidad en José Martí. Estudios Martianos. Memorias del Seminario José Martí (pp. 129-197). Río Piedras: Puerto Rico. 
Ramos, J. (2009). Desencuentros en la modernidad en América Latina: literatura y política en el siglo XIX. Caracas: Fundación editorial el perro y la rana.

Ramos, J. (2014). José Martí: genealogías de la crítica latinoamericana. Revista Andex, 1(1), 3-9.

Rivera, A. (2015). Las artes poéticas en la poesía de Roberto Fernández Retamar. Revista de Crítica Literaria Latinoamericana, 41(82), 241-261.

Rodríguez, G. (2000). La poesía de Roberto Fernández Retamar (En los setenta años del poeta). Unión, 16-22.

Rostagno, I. (1986). Arte poética de Roberto Fernández Retamar. 'Que cualquier cosa sea posible'. Dactylus, 6, 44-46.

Vitier, C. (1971). Roberto Fernández Retamar. Crítica sucesiva (pp. 235-242). La Habana: Contemporáneos, UNEAC.

Waters, M. (2014). Ancient Persia. A concise History of the Achaemenid Empire, 550-330 $B C E$. New York: Cambridge University Press.

Wong, O. (1976). Fernández Retamar y la conciencia crítica. Plural: revista cultural de Excelsior, 61, 61-63. 
